\title{
An evaluation of eThekwini Municipality's regeneration programmes on littering and dumping
}

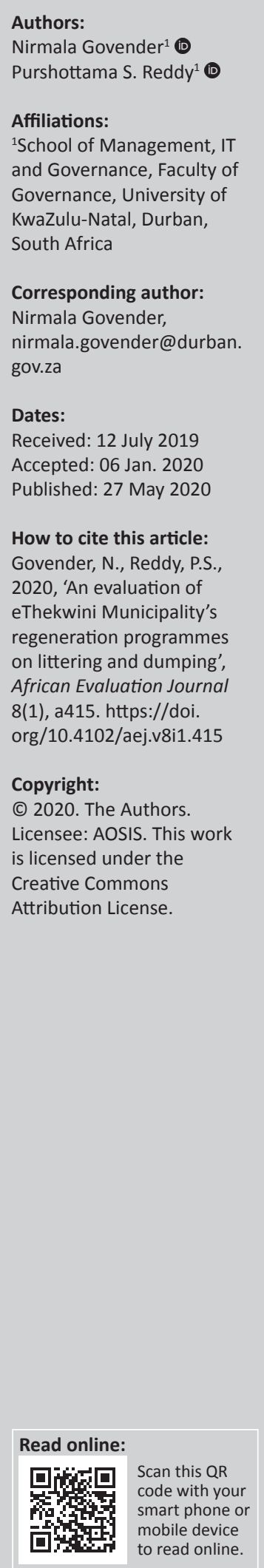

Background: South African cities have been beleaguered with urban deterioration challenges, especially dumping and littering, notwithstanding the regulatory framework and the continuous clean-up programmes undertaken by municipalities. This article identifies the challenges within eThekwini Metropolitan Municipality in addressing littering and dumping, and recommends improvements towards urban regeneration efforts.

Objectives: To critically evaluate compliance of legislation and efficacy of the urban regeneration programmes implemented, which addressed littering and dumping within the inner city of eThekwini Metropolitan Municipality.

Method: This convergent mixed-method research followed a case study approach and involved the analysis of primary data obtained from a qualitative perspective, including semistructured interviews and questionnaires; and secondary analysis of quantitative data in the form of documents and reports obtained from the municipality.

Results: The article identified that urban degeneration, specifically litter and dumping, occurred as a result of ineffective compliance of regulations and lack of enforcement; outdated service levels, lack of monitoring and evaluation of programmes; lack of education initiatives; ineffective leadership and governance; lack of involvement of citizens and businesses in clean city initiatives; and the negative behavioural patterns of citizens.

Conclusion: The key recommendations for municipalities include implementing an integrated strategic plan for urban regeneration within a proactive policy and regulatory environment; monitoring and evaluation of programmes related to urban regeneration; increased resources dedicated to waste management and enforcement; implementing enforcement and consequence management strategies; and stimulating change in the behaviour patterns of citizens, businesses as well as municipality employees.

Keywords: urban degeneration; littering; dumping; by-laws; enforcement; waste management.

\section{Introduction}

Urban degeneration is a challenge that has been experienced in many African countries, including South Africa. The South African Cities Network (SACN) has indicated that one of the main difficulties experienced by various cities of South Africa is 'urban management' (SACN 2016b:53). The massive and complex congregation of population in the urban environment tends to be disordered, leading to untidy spaces, scarcity of resources, air pollution, health concerns, increased traffic challenges, deteriorating and ageing infrastructure, and inadequate waste management (Chourabi et al. 2012). As a result of productivity patterns and urban growth, many cities have a challenge with underused land or distressed and declining urban areas; all these have resulted in the dwindling of city's liveability, image and productivity (World Bank 2018).

South African metropolitan municipalities have been challenged to respond to urban degeneration in a sustainable manner, as resources are generally focused on basic service delivery, such as housing, water, sanitation and electricity, and not on regeneration programmes. Most municipalities in the country are not effectively undertaking service delivery, resulting in local communities progressively losing confidence in local government (Cooperative Governance and Traditional Affairs [COGTA] as cited in Reddy 2015). Attention to the provision of basic service delivery has been intensified because of the ongoing service delivery protests in South Africa. Therefore, South African metropolitan municipalities are continuously challenged by their inability to effectively address urban degeneration. This is confirmed by the SACN which states that municipalities have been sluggish in responding to challenges of urban expansion in an innovative way (SACN 2016a). In order to achieve higher levels of inclusion and integration, 
metropolitan municipalities need to drive development, and physical and spatial transformation (SACN 2016a).

Based on the various challenges and circumstances currently being experienced by cities, the purpose of this research study is to evaluate eThekwini Municipality's compliance with relevant legislation on littering and illegal dumping, and to establish the efficacy of the programmes implemented to address littering and illegal dumping within the inner city of Durban. Littering and illegal dumping of rubbish are regarded as 'forms of waste' and viewed as a behavioural issue, where people without thinking of the consequences dispose items on streets or throw things out of vehicle windows (State of Queensland 2013). Furthermore, illegal dumping refers to the illegal deposit of waste, for example, along roadsides, vacant spaces, waterways, car parks and at locations that are close to urban areas, are relatively isolated, are accessible by vehicles and looks abandoned (State of Queensland 2013).

The main frameworks used as the basis of this study are the Corporate Governance Framework as articulated in the King IV report (Institute of Directors Southern Africa [IODSA] 2016) and the Urban Regeneration Framework by Roberts (2017).

The aim of this research study was to determine whether eThekwini Municipality is compliant in its efforts to address littering and dumping as part of its regeneration programmes and to determine the efficacy of such programmes. The objectives of the research were to critically evaluate compliance to legislation which addresses littering and dumping within the inner city of eThekwini Municipality and the efficacy of the urban regeneration programmes being implemented.

\section{Theoretical and conceptual frameworks which underpin urban regeneration \\ King IV framework}

The King IV report on corporate governance for South Africa, 2016 is defined as the exercise of effective and ethical leadership towards the achievement of governance outcomes (IODSA 2016). The first objective of the King IV report is to 'promote corporate governance as integral to running an organisation and delivering governance outcomes such as ethical culture, good performance, effective control and legitimacy' (IODSA 2016:22). The philosopy which underpins the King IV report is based on sustainable development which is the 'development which meets the needs of the present without compromising the ability of future generations to meet their needs' and 'is a primary ethical and economic imperative' (IODSA 2016:23). This philosophy was used in the appraisal of regeneration programmes of littering and dumping. The main components of the King IV report are integrated thinking, integrating the organisation as part of society, stakeholder inclusivity and corporate citizenship, all of which must exist in an organisation to ensure integrated development (IODSA 2016). The King IV report provides a clear governance platform for organisations undertaking programmes which impact the lives and livelihood of the public.

\section{Urban regeneration framework}

The urban regeneration framework by Roberts (2017:11) identifies six themes which have dominated urban regeneration in the past. These themes include 'Physical conditions and social response; Housing and health; Social welfare and economic progress; Urban growth or shrinkage; Environmental awareness; and Urban policy'. Roberts (2017) confirms that the urban challenges experienced by cities continue to put pressure on policymakers, developers, planners and citizens.

\section{Research methods and design}

Creswell (2014) states that there are three main methods of research design: the qualitative approach, the quantitative approach and the mixed-method approach. This view is supported by Ivankova, Creswell and Clark (2016), who argue that both quantitative and qualitative approaches are the established methods of research design, and the mixedmethods approach is emerging in status. The research design for this study embraces the mixed-methods convergent case study design, which involves the collection and analysis of sets of data that are merged or analysed using joint displays or comparative discussions, as indicated by Creswell and Clark (2018) and Leedy and Ormrod (2016). The case study approach has been adopted for this research because it provides an opportunity for an expanded and comprehensiveunderstanding of the circumstances surrounding the state of cleanliness and attractiveness of the inner city of eThekwini Municipality.

The study site for this research comprises the wards located within the inner city of eThekwini Municipality, which is known as Durban. For the purpose of this research, the names 'Durban' and 'eThekwini Municipality' are used interchangeably as is common amongst citizens. The inner-city area includes the eThekwini Municipal wards 26, 27 and 28 (eThekwini Municipality 2016). The purpose of selecting this study site was that it is the main central business district (CBD) of eThekwini Municipality (eThekwini Municipality 2016) and provides a credible and manageable area for research study.

The target population selected for the study interviews included the following: 154 members of the senior management team of the municipality and 29 councillor representatives of the executive committee, municipal public accounts committee and three ward committees. The target population of the ward committees comprised 33 ward committee members of the three wards of the inner-city area.

Purposive judgement sampling techniques were utilised to identify 16 officials from eThekwini Municipality who were directly involved in the processes identified in this research, and 10 eThekwini municipal councillors as respondents who oversee sub-committees of the council. Four ward committee members per ward were selected by the secretariat of ward committees to complete these surveys. Purposive sampling 
was used to identify five hospitality or entertainment organisations located within the selected sites for questionnaires. The reason for selecting purposive sampling was that the researcher is an employee of eThekwini Municipality and was familiar with the municipal processes, the geographic area and the management and councillors who were actively involved in various aspects of the study topic.

Primary data were collected through interviews, surveys and questionnaires. The data collection tools were piloted prior to commencing the exercise to ensure validity, reliability, integrity and completeness of the process. The surveys and questionnaires for closed questions required respondents to answer specific questions by providing the five scaling options to choose from. A five-point Likert scale was used as a scaling method for surveys and questionnaires having closed questions. The five response alternatives of the Likert scale used are 'Strongly approve, Approve, Undecided, Disapprove and Strongly disapprove' (Clason \& Dormody 1994:32). According to Clason and Dormody (1994:32), the descriptors could be anything and 'the number of alternatives is also open to manipulation'. The use of the Likert scale proved beneficial when surveying the public in the various wards of eThekwini Municipality as it provided a means of measuring respondents' feedback.

Data were captured either by writing or typing responses. All respondents indicated comfort in responding in English and no interpreter was used. The respondents were informed that the interviews could be stopped at any time if so required and that there was no risk involved as individual responses were kept confidential.

Data reports were obtained from municipal departments, as permission from the municipality was obtained by the researcher to utilise data for this study. The quality of data reports was acceptable, as it was obtained directly from municipal departments which used these data reports for decision-making and reporting purposes. It was not possible to determine whether there were any gaps in the data, as the data were documented by the municipal departments and there was no other source to confirm completeness of data. Furthermore, reliance for completeness, accuracy and validity of data was based on municipal departments that are the primary collectors of data. Whilst some of the data collected were recorded on Microsoft Word or Microsoft Excel sheets, other data included documents from external service providers who used scientific methods for data collection. The statistics provided by the departments were sufficient for this study, as it allowed the researcher to undertake trend analysis of certain data and interrogate it for research study. The data collected were maintained in a confidential manner in accordance with ethical considerations.

Audio soundtracks of interviews were converted electronically, whilst manually captured responses were typed on Microsoft Word. Data obtained from ward committee members' surveys, interviews with eThekwini Municipality officials and completed questionnaires from external respondents were analysed and coded using themes. According to Kothari (2004:123), coding is 'a process of assigning numerals or other symbols to answers' so that responses can be specifically allocated to a limited number of appropriate 'categories or classes'.

Secondary analysis of the data collected in the form of reports, documents and interviews was undertaken. The analysis carried out was reflected as descriptive words, as well as visual displays, containing both qualitative and quantitative results, which were converged as identified by Creswell and Clark (2018). Data integration is described as the process in which qualitative and quantitative research interfaces and provides further insight and an enhanced understanding of the findings through the convergence of results from both personal experiences and analysis of statistical data (Creswell \& Clark 2018). An example used in this study is that of quantitative data from the survey questionnaires undertaken by the hospitality industry; more than half of the respondents believed that by-laws were not enforced effectively and that enforcement and visible policing must be intensified, and this belief was corroborated by the qualitative data collected through interviews and questionnaires with various respondents.

Furthermore, the study utilised various research instruments to provide a $360^{\circ}$ view of the study. This process involved secondary analysis of the reports identifying trends. The analysis also provided the views of the respondents from the interviews and surveys undertaken as a primary mode of data collection.

Information collected was kept at a safe location and treated as confidential. All respondents signed informed consent ensuring voluntary and informed participation. Anonymity, human dignity, confidentiality and privacy were guaranteed during the entire research process. Findings were stated in an impartial and truthful manner and without any misrepresentation.

\section{Ethical considerations}

This article followed all ethical standards for a research without direct contact with human or animal subjects.

\section{Results \\ Compliance to legislation}

The first part of the objective of the research required an examination of the obligatory scope of the municipality in dealing with urban degeneration and evaluating gaps between mandatory obligations and municipal programmes addressing these issues. In order to address this objective of the research study, specific legislative and regulatory data associated with the study topic were collected for analysis. The analysis of the legislation and regulations impacting the study revealed that all legislations were enforced by eThekwini Municipality in one way or the other through programmes and municipal by-laws. 


\section{Overview of programmes implemented to ensure a clean and attractive city}

For the second part of the objective of evaluating the efficacy of the programmes identified, both qualitative and quantitative processes were undertaken, which included secondary analysis of municipal data and surveys, and primary analysis of respondent interviews. An overview of the programmes implemented by eThekwini Municipality to address dumping and littering is as follows:

The Cleansing and Solid Waste Unit implemented structured sweeping and cleaning, litter picking, and separation at source, as indicated in the interviews with management. Additionally, management indicated that education officers were stationed at all beach areas, and have access to a fully equipped educational bus, which flights environmental education. In 2012, eThekwini Municipality embarked on a project named 'Clean and Maintain My City' campaign, which aimed at cleaning up the city; this was highlighted in many of the interviews with management and councillors. This was a collaborative effort of the area-based management team and other relevant units. Another programme which was launched in 2017 was 'Operation Spring Clean eThekwini' or Khuculul'i Theku, which, as described by a management respondent from the Cleansing and Solid Waste Unit, was a holistic clean-up campaign. Therefore, it is apparent that a number of initiatives were undertaken by eThekwini Municipality to ensure a clean and attractive city.

\section{Cleanliness of the city}

One of the questions asked of interviewees was the following: 'do you believe that the city of Durban is clean, attractive and well-maintained?' More than $60 \%$ of the municipality management interviewed agreed that the city was either 'not clean' or 'mostly not clean'. Less than $40 \%$ of the municipality management stated that the city was 'clean to some extent'. Interestingly, responses in the various categories of management differed according to the roles that were undertaken by each category of management. Management that were directly involved in the cleaning of the city and were addressing urban degeneration were the ones which indicated that the city was 'clean to some extent'. Strategic management interviewed indicated that the city was 'mostly not clean', whilst the management who managed programmes which were affected by the state of cleanliness of the city indicated that the city was 'not clean'.

The eThekwini Municipality management expressed views that the city was not clean because of informal traders and uncontrolled taxis plying in the city. Furthermore, the city was not clean because service levels for cleaning the city were not adequate, and these were neither monitored nor enforced, as reflected by a respondent:

'Certain areas are clean, but most are not. Because, on the one hand, our mode of delivery is not effective. We can't maintain the service levels that are required on the ground. At the same time, our service levels are not adequately explicit and not properly monitored and enforced.' (Respondent M2, Male, Senior Management)
In addition, the respondents highlighted that education initiatives were lacking, as illegal dumping, emphasised by many of the managers, was contributing to the unsightly view of the city. Even though education programmes were implemented by the Cleansing and Solid Waste Unit, communities continued to dump illegally, which had resulted in the unkempt environs of the city.

In the external hospitality or entertainment industry management survey interviews, 20\% of the respondents believed that the city was 'clean to some extent', $60 \%$ of the respondents believed that the city was 'not clean' and $20 \%$ of the respondents believed that the city was 'mostly not clean'. This was corroborated by the views of eThekwini Municipality councillors, as $90 \%$ of the councillors felt that the city was 'not clean', whilst 10\% indicated that the city was clean. This was further elaborated by councillors' responses as follows:

'No, it is not clean. I think we need to educate people. If you go out, you will notice people don't care, as they dump whatever they're eating anywhere.' (Respondent C5, Male, Counicllor)

The qualitative responses confirm the quantitative data from the survey opinion of the hospitality or entertainment industry on the satisfaction of municipal services in ensuring the cleanliness of the city; $80 \%$ of respondents were slightly unsatisfied with the municipal services of cleaning the city, whilst $20 \%$ were neutral.

A response from a business person identified that the state of cleanliness in the city affected businesses in the vicinity:

'Cleanliness has a material impact on our business, especially because the venue from which we operate is for entertainment and relaxation, and part of that requirement is to have an environment which is conducive to a positive image of cleanliness, hygiene and to be well-maintained to make it inviting to consumers. If the environment is not inviting, this will naturally impact on our consumers looking to visit the venue, which negatively impacts on the business concerned.' (Respondent HE1, Male, Hospitality or Entertainment Industry)

Therefore, the consolidated majority view from municipality management and councillors, as well as respondents from hospitality or entertainment industry, was that the city was not clean and that the respondents were not satisfied with the programmes undertaken by the municipality.

However, even though the stakeholder respondents were not satisfied with the municipality programmes or had opined that the city was not clean, there was no evidence of business or the public being involved in keeping the city clean. Most stakeholders preferred to complain about the lack or effectiveness of municipality programmes in cleaning up the city but did not take any initiative to clean the city.

\section{Lack of sustainable programmes to ensure a clean city}

Respondents from various units driving clean-up programmes in the city stated that the city had embarked on a programme 
in which teams from various units cleaned the city's different spaces; however, a senior manager who was interviewed provided insight into the regeneration programmes of the city as follows:

'The problem with those initiatives is that they are reactionary and populist and draw resources from other areas and are not sustainable.' (Respondent M2, Male, Senior Management)

Sustainability was a concern for respondents:

'Sustainability is about ownership and joint management of a situation, and not about the city's problem alone. At the moment there is too much emphasis on the city not doing its work.' (Respondent M3, Female, Senior Management)

This confirms the hospitality or entertainment industry's comments on 'Clean and Maintain My City' campaign:

'There has been an impact and it has helped, but the Clean My City campaign is not sustainable. The city must acknowledge what is not working.' (Respondent HE2, Female, Hospitality or Entertainment Industry)

\section{Another respondent stated that:}

'We are only doing campaigns and not doing enforcement. There are not enough bins. Give the bins to businesses to sponsor and maintain the bins. Make them a hands-on group. We need aggressive action and clean up. Civic pride is required.' (Respondent C2, Female, Councillor)

One respondent articulated the challenges with having 'Clean and Maintain My City' event-type campaigns:

'Yes, I think the negative tendency is that when it's an event, people don't take it as an everyday type of behaviour, that they expected to follow. It's a once-off project, and then that's it. So, it shouldn't be an event. When it's an event, you don't provide and offer coverage for the city. It's selected areas that benefit.' (Respondent M1, Male, Senior Management)

Undertaking campaigns such as the 'Clean and Maintain My City' campaign is expensive, as articulated by Hing and Gunggut (2012), who opined that such programmes include providing free $t$-shirts, caps and meals to participants but this will not be reciprocated or educate the participants.

The conclusion, therefore, is that the city has failed to focus on the underlying problems leading to an unkempt city. Issues of negative behaviour patterns leading to illegal dumping and littering, continuously and reactively cleaning the city without impacting the state of cleanliness of the city and not educating stakeholders on their roles and responsibilities to ensure a clean city are some of the underlying challenges that the city needs to address.

\section{Limited enforcement of by-laws}

The efficacy of urban regeneration programmes implemented within the inner city of eThekwini Municipality was examined by analysing the fines issued for non-compliance of by-laws related to littering and illegal dumping. Penalties issued for offences committed for non-compliance of by-laws were monitored by management to inform decisions regarding the areas of increased littering and illegal dumping so that resources could be directed to such hotspots.

With the implementation of new by-laws in 2016, the analysis of the 'R3000' fine penalities issued was for the years 2016 to 2017. The analysis revealed that Ward 28 had the highest number of penalties, that is, 23 penalties, issued in 2017 for littering, compared to just two penalties in 2016, whereas Ward 26 reflected 12 incidents in 2017. No fines were levied for littering in Ward 27 in 2016 and 2017. The fines levied for dumping increased substantially in 2016 onwards because of the implementation of new by-laws. Ward 28 featured prominently, with 26 incidents of dumping in 2017, compared to nine in 2016. Ward 26 reflected 12 penalties issued in 2017, which was a massive increase from just three in 2016. Incidents of dumping in Ward 27 increased to seven in 2017, which was the highest that Ward 27 has experienced in all categories of penalties.

Survey questionnaires of the hospitality or entertainment industry revealed that $60 \%$ of its respondents did not agree that the by-laws were effectively enforced; $40 \%$ of the respondents were neutral. This was corroborated by a respondent:

'By-laws are sufficient, but what is happening on the ground is not sufficient, as there are no human resources for enforcement.' (Respondent M16, Male, Senior Management)

In contrast, a respondent commented on the sufficiency of by-laws as follows:

'There is a need to review all by-laws as they are not sufficient and can't be enforced.' (Respondent M15, Female, Management)

A respondent (Respondent M16, Male, Senior Management) stated that resources for enforcement were deployed only for a 40-h week, and because of budgetary constraints, there was limited overtime available to undertake enforcement after working hours.

The views of internal and external respondents reflected that by-laws were either insufficient or not enforced effectively, and that there were insufficient resources to effectively implement these by-laws. Although the municipality has bylaws in place to address litter and dumping, the city needs proper enforcement of these laws. However, critical to this process of enforcement was the lack of enough staff to enforce these bylaws. The municipality's multi-unit task team dealing with the issues of urban degeneration must be enhanced. Furthermore, consequence management strategies are to be identified and enforced. Naming and shaming should be implemented so that the public could know that the city is serious about its programmes and those found not complying with laws would be fined or imprisoned. This would send a strong message to the public ignoring by-laws.

\section{Lack of coordination of programmes in addressing urban degeneration}

With reference to the municipality's programmes in dealing with urban degeneration, $67 \%$ of the ward committee 
members were 'not satisfied' and this view was also supported by the hospitality or entertainment industry, where $60 \%$ respondents were 'slightly unsatisfied' and $20 \%$ were 'totally unsatisfied' with the programmes managed by the municipality in dealing with urban degeneration. However, even though these various stakeholders were mostly not satisfied with the municipal response to urban degeneration, not much effort was made by business/ industry or the public in actively participating in urban regeneration programmes and they continued to rely on municipality to undertake these programmes.

Similarly, the lack of coordinated services was a concern raised by respondents. The example provided by respondents was the cleaning of verges, where tenders were issued only for cutting and removal of grass. Therefore, when contractors cleaned verges, solid waste was left behind, and very often the waste was swept into stormwater drains. The issues of outdated service standards, operating procedures and structures were challenges identified during the interviews. The theoretical framework provided by Roberts (2017) on urban regeneration highlights the review of existing strategies as a matter to be considered for regeneration programmes.

\section{Outdated practices}

Significant problems plaguing the eThekwini Municipality were the current process flows and operating procedures, which although implemented were not monitored properly. Furthermore, it was highlighted by respondents that the operating procedures were outdated and not relevant in current circumstances. Outdated processes hinder efforts to clean the city, as city migration results in more inhabitants settling within the city, resulting in increased litter and waste. Therefore, without updating the processes to address changed circumstances, the city could continue to fail in being sustainably clean.

\section{Lack of involvement of public and businesses in clean-up programmes}

Most of the ward committee members stated that the public was not participating in clean-up programmes in the city, and a number of respondents identified that this was because of the public not believing that they should be involved in cleaning programmes. Furthermore, the public attitude, as identified in the study, was that they create jobs by throwing dirt on streets. Therefore, the lack of education of the public and other stakeholders has been a huge concern of both councillors and management. Education and awareness sessions should be held in the city for different groups of stakeholders, including the public, formal and informal businesses, including street vendors, and most importantly employees of the municipality. In the case of eThekwini Municipality, more than 25000 employees could be practically educated about littering and illegal dumping. These employees could then be ambassadors of the city to share messages with families and friends. The target audience would grow substantially. Strategic communication messages providing the public and businesses with the ideas of keeping the city clean should be shared across all platforms. Businesses should be encouraged to partner with the municipality to keep the city clean through precinct management programmes, where businesses make monthly contributions towards teams of people who clean and provide security to the precinct.

\section{Lack of leadership and governance}

Leadership and governance were highlighted in the study through the conceptual framework as well as by respondents. Some of the respondents highlighted that getting votes was the main concern of municipality leadership. The Department of Planning, Monitoring and Evaluation (DPME) has highlighted these challenges in the years since democratisation, which included a 'lack of political leadership; political interference and patronage' (Republic of South Africa 2014:10). The element of leadership as the factor to be considered in an organisation is also highlighted in the King IV report (IODSA 2016), which provided a point of confirmation for the challenges identified.

\section{Negative social behaviour patterns of citizens}

Negative social behaviour patterns of citizens were highlighted by a number of respondents as contributing towards urban degeneration. People continuously litter streets and illegally dump waste with no consideration. It was identified that one of the unintended consequences of the municipality continuously cleaning the city is that citizens rely on daily clean-up and therefore continue to litter and dump intentionally. Lack of pride of residing in the city was the element raised in the study by many respondents. The research indicated that people never participated in cleaning of the city to the extent that should be. This is confirmed by the World Bank which highlights that the relics of the apartheid era have resulted in widespread service delivery protests and resultant behaviour patterns (World Bank 2018). The media has identified vagrancy, squatting, drug addicts and criminal behaviour within the inner city, which have contributed towards urban degeneration. This is confirmed by the criteria in Robert's (2017) framework, which highlights that citizen engagement is one of the areas which needs to be focused on when establishing a regeneration framework for municipality.

A programme driven to inspire positive change in social behaviour patterns and instil civic pride could enhance the success of any project. Programmes inspiring social change in the behavioural patterns of an organisation, where training sessions, as well as awareness sessions, are scheduled for all employees, with roles and responsibilities and the contribution of employees towards the strategy of the organisation, must be implemented. A sense of pride must be instilled in employees through social media and communication. Similarly, programmes must be implemented to address the ethos of the public and corporate businesses on responsibilities related to ensuring that the environment is clean, attractive and well-maintained. 
Many of the respondents interviewed in the study highlighted that both formal and informal businesses within the inner city of Durban were responsible for the current state of decline and decay. It is apparent that businesses have become complacent and believe that only the municipality is responsible for the cleaning up of the city and dealing with urban degeneration. The focus on business is highlighted in the King IV framework (IODSA 2016), which provides details of corporate citizenship as one of the areas that needs to be addressed.

Therefore, although city officials have elaborated that many programmes are undertaken to deal with litter and dumping, the respondents opined their dissatisfaction towards such programmes.

\section{Discussion}

The findings of this research study are that by-laws and regulations are not enforced effectively either because of their ineffectualness or due to ineffective processes. Inadequate and outdated service levels and a lack of monitoring, lack of educational initiatives for the public and municipal staff for maintaining a clean city, ineffective leadership and governance processes, negative behavioural patterns of citizens and lack of involvement of businesses in keeping the city clean have contributed towards urban degeneration.

Based on the findings of this study, the following framework of elements is recommended to be focused by municipalities to begin the journey of addressing urban regeneration.

- Leadership and governance responsibilities

- Integrated strategic planning

- Communication across different platforms

- Stakeholder involvement and partnerships

- Education of employees and public

- Instilling pride in the city and influencing social behavioural patterns

- Encouraging stakeholder participation and involvement from the beginning of the process

- Education on laws and impacts on the environment and economy

- Effective by-laws and policies

- Use of digital technology

- Monitoring and evaluation.

The strength of the study methods is that the qualitative methods confirm the quantitative data. Furthermore, the frameworks identified for the study support the findings and the recommendations derived from the study. The limitation of the methods used is that it may not be possible to replicate the results of the research to other municipalities because of different circumstances in each municipality.

Further research suggests identifying the effective involvement of communities and businesses in cleaning programmes and reporting dumping and littering, identifying the type of awareness and education programmes which would work best within the context of South Africa, investigating the effective enforcement of by-laws within municipalities and exploring the role of employees of an organisation in influencing public awareness and behaviour.

\section{Conclusion}

The study evaluated eThekwini Municipality's compliance to legislation and efficacy of the urban regeneration programmes implemented to address littering and dumping within the inner city. The results of the study findings reveal that although the municipality has programmes in place to address the various pieces of legislation on littering and dumping, these programmes are ineffective. The municipality is in a compliance mode, which fails to bring about a change in the municipal environment.

The study revealed that although management of the implementing departments of the municipality believe that the programmes are effective, this is contrary to the view of public, councillors and management who are not directly involved in the programmes. The responses from councillors, representatives of the hospitality or entertainment industry, ward committee members and management of the municipality reveal that the programmes are not effectively addressing littering and dumping, and service levels are outdated. Furthermore, the view is that by-laws are not enforced properly. Another clear gap is that the programmes are not monitored and evaluated to determine efficacy. Educating stakeholders on the roles and responsibilities regarding urban regeneration is a recommendation by many of the stakeholders. Leadership and governance are key to transform the city's clean-up programmes.

In order for cities to effectively implement urban regeneration programmes, this study recommends transparent and dynamic leadership; integrated strategic planning and collaboration; a proactive policy environment; increased resources in waste management; enforcement and consequence management strategies; internal and external programmes to facilitate behavioural change; awareness and education sessions with citizens and businesses; effective technology and communication; and monitoring, evaluation and performance management.

\section{Acknowledgements}

The author acknowledges and thanks Prof. P.S. Reddy (doctoral promoter) for his guidance; the Ethekwini Municpality, its Councillors and Management for access to information and knowledge; and the Hospitality and Entertainment Industries for participation in the study.

\section{Competing interests}

The authors have declared that no competing interests exist.

\section{Authors' contributions}

N.G. undertook the research and identified the findings, and P.S.R. supervised the research and edited the article, ensuring its appropriateness and readiness for submission. 


\section{Funding infromation}

This research received no specific grant from any funding agency in the public, commercial or not-for-profit sectors.

\section{Data availability statement}

Data sharing is not applicable to this article as no new data were created or analysed in the study.

\section{Disclaimer}

The views and opinions expressed in this article are those of the authors and do not necessarily reflect the official policy or position of any affiliated agency of the authors.

\section{References}

Chourabi, H., Nam, T., Walker, S., Gil-Garcia, J.R., Mellouli, S., Nahon, K. et al., 2012 'Understanding smart cites: An integrative framework', in Proceedings of the 45th IEEE Hawaii International Conference on System Sciences, Hawaii, 04-07 January2012, pp. 2289-2297, IEEEComputer Society, Washington DC, United States.

Clason, D.L. \& Dormody, T.J., 1994, 'Analysing data measured by individual Likert type items', Journal of Agricultural Education 35(4), 31-32. https://doi.org/10.5032/ jae.1994.04031

Creswell, J.W., 2014, Research design - Qualitative, quantitative and mixed methods approach, 4th edn., Sage, Thousand Oaks, CA.

Creswell, J.W. \& Clark, V.L.P., 2018, Designing and conducting mixed methods research, 3rd edn., pp. 103-185, Sage, Thousand Oaks, CA.
eThekwini Municipality, 2016, eThekwini inner-city local area plan, eThekwini Municipality, Durban.

Hing, C.K. \& Gunggut, H. 2012, 'Maintaining urban cleanliness - A new model', Procedia Social and Behavioural Sciences 50, 950-958. https://doi.org/10.1016/j. sbspro.2012.08.096

Institute of Directors Southern Africa (IODSA), 2016, King IV: Report on corporate governance for South Africa 2016, Institute of Directors in Southern Africa, Johannesburg.

Ivankova, N.V., Creswell, J.W. \& Clark, V.L.P., 2016, 'Foundations and approaches to mixed methods research', in K. Maree (ed.), First steps in research, 2nd edn., pp. 306-308, Van Schaik, Pretoria.

Kothari, C.R., 2004, Research methodology research and techniques, pp. 2-123, New Age International, New Delhi.

Leedy, P.D. \& Ormrod, J.E., 2016, Practical research: Planning and design, 12th edn., Merrill Prentice Hall, Upper Saddle River, New Jersey.

Reddy, P.S., 2015, 'Post-1994 local governance and development in South Africa: Quo vadis?', in P.S. Reddy \& V.S. De Vries (eds.), Quo vadis? Local governance and development in South Africa post-1994, pp. 323-340, Bruylant, Brussels.

Republic of South Africa, 2014, Twenty-year review: South Africa - 1994 to 2014 Background paper, Local Government, Department of Planning, Monitoring and Evaluation, Pretoria.

Roberts, P., 2017, 'The evolution, definition and purpose of urban regeneration', in P. Roberts, H. Sykes \& R. Granger (eds.), Urban regeneration, 2nd edn., pp. 9-44 Sage, London.

South African Cities Network (SACN), 2016a, State of South African cities report 2016, SACN, Johannesburg.

South African Cities Network (SACN), 2016b, Beyond gentrification: Exploring alternatives to urban renewal, SACN, Johannesburg.

State of Queensland, 2013, Queensland's litter and illegal dumping action plan - October 2013, Department of Environment and Heritage Protection, Queensland.

World Bank, 2018, Urban regeneration, viewed 04 August 2018, from https://urbanregeneration.worldbank.org/ 